\title{
Nota biográfica em comemoração ao nascimento de Eny Caldeira
}

\section{Maria Elisabeth Blanck Miguel ${ }^{1}$}

Registrar algumas notas biográficas sobre uma professora que marcou profundamente o cenário educacional não só de Curitiba, mas do Paraná, e que atuou ainda ao lado de Anísio Teixeira, poderia parecer algo fácil, pois seria possível nos atermos tão somente à sua vida, atividades e funções que exerceu. No entanto, não se trata de uma professora comum, que, no caso, também mereceria maior atenção na análise e na descrição, pois o cotidiano de uma sala de aula e a convivência com os alunos é um caminho pontilhado de alegrias, relacionamento humano, superações e aprendizagens. Porém, trata-se de escrever sobre a Professora Eny Caldeira, mestra singular no cenário da educação paranaense.

Acreditamos que as notas biográficas possam ser escritas a partir de três perspectivas: da pessoa, da professora e da pesquisadora. Será difícil separar as três dimensões. Eny Caldeira era todas e mais que isso. Algo que nós, seus alunos, sentíamos e ela nos transmitia, mas que não conseguíamos definir. Porém, permanece indelével conosco. E, aqui, já estamos a falar sobre a pessoa e a professora. Mas, tentemos, ao menos, trabalhar em primeiro lugar com alguns dados de sua biografia.

Eny Caldeira nasceu em Prudentópolis, interior do Paraná, em 23 de outubro de 1916. Cursou a Escola Normal no Instituto de Educação do Paraná. Em 1935 iniciou sua atuação como professora primária e, em 1939,

[...] ingressou no curso de Pedagogia da Faculdade de Filosofia, Ciências e Letras do Paraná (FFCLP/PR), formando-se em 1941, tanto no bacharelado como na licenciatura em Pedagogia, integrando a segunda turma de bacharéis e a primeira turma de licenciados da Instituição. (OSINSKI; SILVA, 2016, p. 118).

DOI: $10.1590 / 0104-4060.49144$

1 Pontifícia Universidade Católica do Paraná. Programa de Pós-Graduação - Mestrado e Doutorado em Educação. Curitiba, Paraná, Brasil. Rua Imaculada Conceição, no ${ }^{\circ} 1155$. CEP: 80215-901.E-mail: maria.elisabeth@pucpr.br 
Era neta de Jerônimo Durski, professor polonês diplomado pelo Seminário Real Católico do Reino da Prússia e que exerceu atividades educacionais em várias escolas do interior do Estado, na segunda metade do século XIX. Durski, em ofícios e relatórios que escreveu às autoridades paranaenses, mostrava-se inconformado com as condições das escolas e do trabalho do professor, à época. Este inconformismo, a coragem de conhecer outros países e outras realidades e a vontade de mudar as condições educacionais também fizeram parte do modo de ser da Professora Eny Caldeira.

Tais características levaram-na à Europa, onde, em Perúgia (Itália), frequentou cursos no Studi Pedagogico. Nesta Instituição conheceu Maria Montessori, segundo ela, "um ser iluminado". Ali entrou em contato com o método organizado pela médica e pedagoga, a princípio, para as crianças com necessidades especiais, então consideradas "excepcionais". Este método foi posteriormente aplicado às crianças "normais", dando origem ao método montessoriano, até hoje utilizado em muitas escolas.

Aramis Millarch, jornalista que provavelmente a entrevistou, como demonstra o artigo publicado no Jornal Estado do Paraná, em 17/03/1991, que traz o depoimento da própria Professora Eny, dizendo um pouco do que ela viu e fez durante o período em instituições europeias, na busca de novos conhecimentos. Diz ele:

Eny freqüentou o Instituto de Psicologia da Universidade de Roma e, em Paris, obteve os certificados de "Good Attendance" junto a Unesco e o da "L'Ecole Pratique de Hautes Etudes", junto ao Laboratório de Psycobiologia de l'Enfant, isto já em 1952. Na Suíça, onde residiu por algum tempo, também freqüentou a escola experimental desenvolvida por Jean Piaget - "que embora tivesse uma outra filosofia de educação, foi importante para minha formação". - "Em Paris, especialmente, as aulas de Merleau Ponty e do padre Lebret foram fascinantes". (MILLARCH, 1991, não paginado) $)^{2}$.

Mas, o que realmente Eny trouxe de tudo que viu e ouviu nos cursos frequentados foi o novo modo de ver e conceber o educando, assim como de trabalhar com ele. E, certamente, o amor que dedicava à educação, encontrou

$2 \mathrm{O}$ artigo está disponibilizado no site: $<$ http://www.millarch.org/artigo/professora-eny-que-trouxe-o-metodo-montessoriano-para-o-parana > . Acesso em: 18 set. 2016. 
lá os ingredientes necessários para alicerçarem a prática que exerceu quando de seu retorno ao Brasil.

Naquele período, as ciências alicerçavam a Pedagogia dando-lhe os fundamentos e caracterizando a Escola Nova, enquanto preparação do homem para a sociedade industrial. Tal concepção se fazia presente nas escolas, principalmente nas Escolas Normais. As professoras que atuavam nos cursos de Pedagogia e que haviam recebido como primeira formação a de professora primária, nessas instituições ${ }^{3}$, embora conservassem resquícios da pedagogia tradicional, aplicavam tais conceitos e realizavam suas práticas. Dentre tais conceitos e práticas, estava a compreensão do aluno como sujeito e centro da aprendizagem, dando ao professor a função de estimulador e facilitador do processo, respeitando o desenvolvimento do educando e considerando as etapas da aprendizagem.

Eny não só compreendeu tais pressupostos e conceitos, como viveu todos eles, dando-lhes um colorido novo, a partir da sua própria forma de ser e de entender o mundo e a profissão docente, que para ela era uma missão. Tinha do aluno uma visão ideal, fundamentada na concepção da criança, em Montessori:

[...] devemos considerar a criança como o destino da nossa vida futura. Quem quiser obter qualquer benefício para a sociedade tem necessariamente de se apoiar na criança, não só para a salvar dos desvios, mas também para conhecer o segredo prático da nossa vida. Deste ponto de vista a figura da criança apresenta-se forte e misteriosa, ocultando em si o segredo da nossa natureza. Deve-se meditar sobre ela para que se torne o nosso mestre. (MONTESSORI, 1969, p. 303-304).

Porém, o modo como Eny percebia a criança, se por um lado era influenciado pelas concepções mais idealizadas, por outro era permeado pelas condições reais que moldavam a vida dos alunos, principalmente daqueles que frequentavam os cursos primários das escolas públicas.

Estas sempre se constituíram como o lócus de atenção da educadora. Assim, em "1952, Eny organizou na Vila Tinguí, a Escola Experimental Maria Montessori. Em 1953 trabalhando no Instituto de Educação do Paraná, reorganizou o Jardim da Infância daquela Instituição, seguindo o modelo montessoriano". (MIGUEL, 2016, p. 177). O seu interesse pela escola pública e a qualidade de

3 Algumas já nominadas como Institutos de Educação porque ofereciam cursos de especialização do magistério e de habilitação para administradores escolares do grau primário, segundo previa o Decreto-Lei n ${ }^{\circ} 8.530$, de 2 de janeiro de 1946: Lei Orgânica do Ensino Normal. 
seu trabalho constituíram-se nos motivos pelos quais Anísio Teixeira convidou-a, em 1955, para trabalhar como pesquisadora, no Instituto Nacional de Pedagogia ${ }^{4}$. Conforme Eny declarou a Millarch, "Durante cinco anos pude fazer um trabalho amplo e com bons resultados. Coordenei a reforma da educação no Rio Grande do Norte e fiz pesquisas no Nordeste e Brasil Central, organizando também a escola normal de Caicó". (MILLARCH, 1991, não paginado) 5 .

Tal como Montessori, que, embora se utilizasse de uma linguagem idealizada sobre a criança, desenvolveu sua prática com crianças excepcionais e mais tarde em escolas públicas, Eny Caldeira orientou as aulas que ministrou junto ao curso de Pedagogia da Universidade Federal do Paraná, na perspectiva do trabalho com as escolas públicas. Sua concepção de pesquisa era aquela que se realizava a partir da prática, isto é, seus alunos observavam as crianças no quotidiano escolar, colhiam dados sobre a realidade vivida por elas e o conjunto de observações e dados era discutido nas reuniões que aconteciam no Laboratório de Ensino e Aprendizagem.

Na década de 1960, antes de ser implantada a Reforma Universitária (Lei $\left.\mathrm{n}^{\circ} 5.540 / 68\right)$, Eny desenvolvia suas atividades docentes em uma sala que se diferenciava das outras, com móveis dispostos de modo a favorecer as discussões, não havendo distinção entre o lugar do professor e os lugares dos alunos. Todos se sentavam em torno de uma mesa retangular, de tamanho grande, cercados por gravuras e quadros dispostos nas paredes, representando figuras e cenas da educação. Também livros e revistas compunham o ambiente, constituindo-se em material que abordava fatos e questões educacionais. Dentre o acervo que Eny dispunha, salientavam-se os específicos do método de Maria Montessori, que a mestra havia trazido da Itália ${ }^{6}$.

Eram, a princípio, levantadas as principais questões que afetavam a educação das crianças nas escolas públicas da cidade, e por generalização, do Estado e do País. Escolhida uma, dentre as principais que afetavam o desenvolvimento

4 O Inep foi criado, por lei, no dia 13 de janeiro de 1937, sendo chamado inicialmente de Instituto Nacional de Pedagogia. No ano seguinte, o órgão iniciou seus trabalhos de fato, com a publicação do Decreto-Lei $n^{\circ} 580$, regulamentando a organização e a estrutura da instituição e modificando sua denominação para Instituto Nacional de Estudos Pedagógicos. Foi nomeado para o cargo de diretor-geral do órgão o professor Lourenço Filho (História do Inep): <http://portal. inep.gov.br/institucional-historia acesso em 18/09/2016>. Acesso em: 18 set. 2016. Anísio Teixeira assumiu a direção do Inep em 1952.

5 Artigo de Aramis Millarch já citado.

6 Tivemos a oportunidade de usar este material, que nos foi emprestado por Eny Caldeira, para uma atividade realizada junto às alunas do Curso Normal do Colégio Sagrado Coração de Jesus, em 1963, em atividade na qual expusemos o método montessoriano, a utilização do material e as finalidades de sua aplicação. Esta atividade fazia parte das propostas da disciplina Didática Especial. (Nota da autora). 
e a aprendizagem dos alunos, essa passava a nortear as visitas para observações nas escolas públicas, sobre a questão escolhida. Tais observações, após serem registradas, eram discutidas no encontro semanal dirigido pela Professora Eny, enquanto aula. Os resultados das discussões, bem como de todas as atividades vividas nas aulas, os alunos os registravam em dossiês. Ao final do semestre, discutiam os resultados das pesquisas, após os interpretarem fundamentados teoricamente, quando então chegavam a uma conclusão sobre a questão investigada.

Conforme citado acima, o trabalho não se limitava às observações, discussões e registros. Outras atividades eram também planejadas e vividas pelo conjunto dos alunos de Pedagogia que cursavam a disciplina de Didática Especial ( $4^{\circ}$ ano de Pedagogia em 1963). Essas atividades poderiam ser realizadas como aulas de demonstração de metodologias em escolas de formação de professores, assistência de defesas de dissertações (após a implantação do Programa de Pós-Graduação em Educação na Universidade Federal do Paraná (UFPR), criado em 1974 e instalado em 1975), bem como participação em palestras ministradas por educadores e personalidades que visitavam o Curso de Pedagogia da Faculdade de Filosofia, Ciências e Letras da UFPR.

Após a implantação da Reforma Universitária, Eny absorveu as diretrizes propostas, como a do trabalho por objetivos comportamentais, sem deixar de lado a concepção de educação que norteou sua trajetória enquanto professora: a crença na educação e, sobretudo, nas possibilidades do educando. Porque acreditava verdadeiramente neste ideário, ela marcou a vida de seus alunos, imprimindo-lhes, indelevelmente, a crença no valor da educação. Como pessoa, profissional e pesquisadora, ela foi, sobretudo, educadora comprometida com a Educação brasileira.

\section{REFERÊNCIAS}

HISTÓRIA DO INEP. Portal do INEP. Disponível em: <http://portal.inep.gov.br/ institucional-historia acesso em 18/09/2016>. Acesso em: 18 set. 2016.

MIGUEL, M. E. B. Homero Braga e Eny Caldeira: Direcionadores da formação científica dos pedagogos (Faculdade de Filosofia, Ciências e Letras da Universidade Federal do Paraná, 1960-1963). In: VIEIRA, C. E.; GONÇALVES. N. G. (Org.). Setor de Educação e Curso de Pedagogia na Universidade Federal do Paraná (1938-2014): Histórias, memórias e desafios contemporâneos. Curitiba: Editora UFPR, 2016. p. 171-186. 
MILlARCH, A. O Estado do Paraná, 17 mar. 1991. Disponível em: <http://www. millarch.org/artigo/professora-eny-que-trouxe-o-metodo-montessoriano-para-o-parana> . Acesso em: 18 set. 2016.

MONTESSORI, M. A criança. Lisboa: Portugália, 1969. 319 p.

OSINSKI, D. R. B.; SILVA, J. P. S. Eny Caldeira e o Ideário Piagetiano na UFPR: A criança e o planejamento urbano (1975-1978). In: VIEIRA, C. E.; GONÇALVES, N. G. (Org.). Setor de Educação e Curso de Pedagogia na Universidade Federal do Paraná (1938-2014): Histórias, memórias e desafios contemporâneos. Curitiba: Editora UFPR, 2016.

Texto recebido em 03 de novembro de 2016.

Texto aprovado em 04 de novembro de 2016. 